\title{
Bearing capacity and stiffness of pile group foundation
}

\author{
Arnoldas Norkus ${ }^{1}$, Vaidas Martinkus ${ }^{2}$ \\ ${ }^{1}$ Laboratory of Geotechnics, Vilnius Gediminas Technical University, Vilnius, Lithuania \\ ${ }^{2}$ CSD Engineers, Vilnius, Lithuania \\ E-mail: 'arnoldas.norkus@vgtu.lt (corresponding author)
}

\begin{abstract}
Pile group foundations are widely employed in geotechnical design. Bearing capacity increment/reduction of pile group (PG) foundation in design practice often described via empirical efficiency factor (EF), a multiplier to sum of single piles (SP) resistances, when they act isolated. The magnitude of EF depends on spacing of SP in PG, soil parameters, configuration of piles, friction of soil-pile, etc. Proposed predictions for choosing the EF magnitude are contradictory. The tests of displacement SP and PG tests conducted in laboratory conditions for 2 spacing cases, ground stress-strain evolution of PG analyzed. The EF magnitude reproduced from tests results compared with proposed by different authors predictions. The pronounced effect of installation sequence to displacement SP response measures, when acting in PG estimated during the tests. From practical point, this phenomenon if ignored for certain connection case of superstructure with PG cap and that of SP with PG cap may cause unexpected PG foundation movements, subsequently resulting the additional stressing of superstructure and foundation. SP installation effect for displacement PG foundation measures of ground response should be properly evaluated in design of constructional elements of superstructure and foundation.
\end{abstract}

Keywords: displacement pile group, test, bearing capacity, efficiency factor.

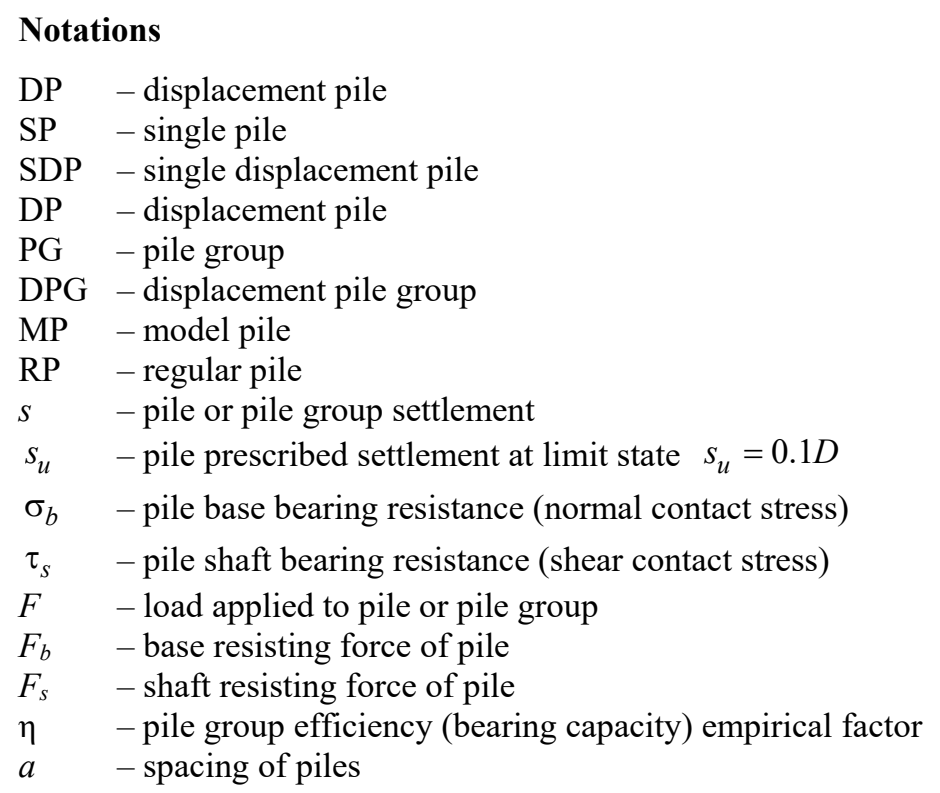

\section{Introduction}

The prediction of behavior of structures interacting with soil is one of the main challenges in structural design. Proper evaluation of soil-structure interaction ensures rational design solution of superstructure and foundation. The identifying relevant foundation movements of foundation is one of the main problems in analysis of structural system: superstructure-foundation-ground (soil mass in vicinity of foundation). Proper evaluation of soil-structure interaction contributes the rational constructional design of superstructure and foundation avoiding possible violation the requirements 
for ultimate and serviceability limit states due unpredicted additional stressing of structural system. Due problem complexity and despite numerous experimental and numerical studies, resistance predictions of pile group foundations are scattered and insufficient, partial empirical relations dominate. The experimental study is dedicated to analysis of bearing capacity and deformation behavior of short displacement pile group prototype with flexible pile cap, subjected by static vertical compressive load. Particular attention addressed to the resistance-stiffness evolution of single piles acting in pile group of different spacing. The short displacement pile groups testing results employed for verification of known models for prediction pile group bearing resistance.

\section{Ground resistance of pile and pile group}

Ground bearing resistance to single pile (SP) loading is determined in terms of stress distribution states under pile base $\sigma_{b}$ and along pile skin surface $\tau_{s}$ at all loading stages. SP ultimate bearing capacity is described via its ultimate load $Q_{u}$, corresponding to ground resistance at deformation stage when prescribed ultimate settlement $s_{u}$ achieved. This "conditional" ultimate limit state criterion usually dominates in design practice. In terms of point forces $Q_{u}$ and the submerged pile effective weight load $W_{\text {pile }}^{\prime}$ equilibrated by the shaft resisting force $Q_{s u}$ and the base resisting force $Q_{b u}$, as follow:

$$
Q_{u}+W_{p i l e}^{\prime}=Q_{b u}+Q_{s u}=\sigma_{b} \cdot \frac{\pi \cdot D^{2}}{4}+\pi \cdot D \cdot \int_{0}^{L} \tau_{s} \cdot d z,
$$

where $L, D, \sigma_{b}$ and $\tau_{s}$ are pile length, diameter, base bearing (base contact stress) and shaft bearing (shaft contact stress) resistances, respectively. As pile base and shaft maximum resistances mobilized not simultaneously, the ultimate pile bearing capacity corresponds the ground stress state for fixed relative pile $s_{u}=0.1 D$ (European Committee for Standardization [CEN], 2004). Note that distribution of $\sigma_{b}$ and $\tau_{s}$ for SDP generally is nonlinear in all stages of ground deformation only their shape change due development of "pseudo elastic" and plastic stresses and strains (see in Martinkus, Norkus, Statkus, \& Zilioniene, 2014). The bearing resistance and stiffness of DPG foundation depend on ground complex elastic-plastic stress-strain evolution peculiarities due the soil-pile-soil interaction acting in group.

For practical purposes in geotechnical engineering, the approach to evaluate the total bearing resistance of pile group (PG) in terms of bearing resistances of isolated SPs adopted. A primary concept of PG efficiency (bearing capacity increment/reduction) was realized via the empirical factor $\eta$, a multiplier to sum of SP bearing capacities acting in group. Kishida (1964) concluded, that $\eta$ in sands depends on: 1) pile spacing ratio $a / D$, where $a$ is spacing of piles; 2) PG configuration; 3) peak friction effective angle $\varphi_{p}$. He reported that for $a / D=2$ the $\eta$ varies within bounds of 0.8 and 2.5. The larger magnitude was proposed for sand with $\varphi_{p}{ }^{\circ}=30^{\circ}$ and the smaller one for $\varphi_{p}{ }^{\circ}>45^{\circ}$. He stated $\eta=1$ (id. est. independent on $\varphi_{p}{ }^{\prime}$ ) is for $a / D \geq 6.5$. Vesic (1969) the analogous experimental findings summarized by: 1) $\eta$ related only to $\tau_{s}$ of SPs, id. est. $\eta=\eta_{s} ; 2$ ) $\eta_{\max }=3$. (Tejchman, 1973) summarized PG test results in loose and dense sands by: 1) $\eta \geq 1$ for various PG configurations; 2) reduction of $a$ increases PG bearing capacity. Broms (1981) analyzed variation of $\eta$ by performing PG tests with small scale piles made of different materials with rough and polished surfaces. His findings were in line with Kishida ones, but in conflict with Vesic and Tejchman conclusions. Q.-Q. Zhang, S.-M. Zhang, Liang, Q. Zhang, and Xu (2015) tested and simulated numerically the PGs connected by rigid cap. His findings were summarized by: 1) settlement $s$ of PG decrease for smaller $a$ at the same loading level; 2) $\eta$ increment is compatible to $a$ increment; 3) $s$ of PG decrease when increasing $a$ and with increasing the number of piles. Sales Prezzi, Salgado, Choi, and Lee (2017) tested PGs in sands of various densities. The findings were summarized by: 1) spacing $a$ in sand has minimal effect when $a / D>4 ; 2) \eta>1$ is for loose to medium dense sand, while in dense sand $\eta<1 ; 2$ ) the driving effects of SPs has the impact on the load-settlement response of PGs with spacings $a=2 D, 3 D$, whereas for $a=4 \mathrm{D}$ installation effects are negligible.

Fleming, Weltman, Randolph, and Elson (2009) proposed a concept of conditional foundation for PG response analysis. The PG considered as particular block of soil reinforced by piles with two available failure modes: 1) failure of individual SPs; 2) failure of soil block. He presented the following failure scenarios forecasts: 1) PG of large number of long slender piles is more likely to fail as block of soil when compared with foundation of short stubby piles with same spacing; 2) soil block failure in sand is less likely for piles in clay.

Randolph (2003) for $s$ prediction developed the equivalent raft method, adopting the PG foundation as the massive rigid particular soil block. However, despite a long term of usage, the method has significant shortcomings as ignoring the number of significant factors, namely: reciprocal pile interaction, installation technology, pile cap stiffness, uneven distribution of ground stiffness. One can mention investigations of numerical simulation of PG response (Bhasi, Rajagopal, \& Reddy, 2010; Comodromos, Anagnostopoulos, \& Georgiadis, 2003; McCabe \& Lehane, 2006; other). The settlement $s$ of individual pile acting in PG generally is determined by using a superposition of interaction factors. In 
investigations (Mylonakis \& Gazetas, 1998; Randolph \& Wroth, 1979) the interaction coefficient $\alpha$ introduced. Coefficient defined a fractional SP $s$ increment, resulting from presence of loaded adjacent SPs. the method applies when the PG cap is relatively flexible. When PG cap is rigid, the condition of equal $s$ for all individual SPs acting in PG fulfilled.

All aforementioned and other analytical, empirical, numerical methods, proposed formulae for prediction of PG response measures developed for solving actual practical problems.

\section{Experimental set-up, ground characterization, pile and pile group testing procedures}

Pile tests conducted under laboratory conditions in specialized soil test box (Figure 1) creating artificial sand deposit with controlled properties per depth (see CPT data in Figure 2). Due performed laboratory tests results the sand soil is characterized dense sand (incl. relative density 79\%).

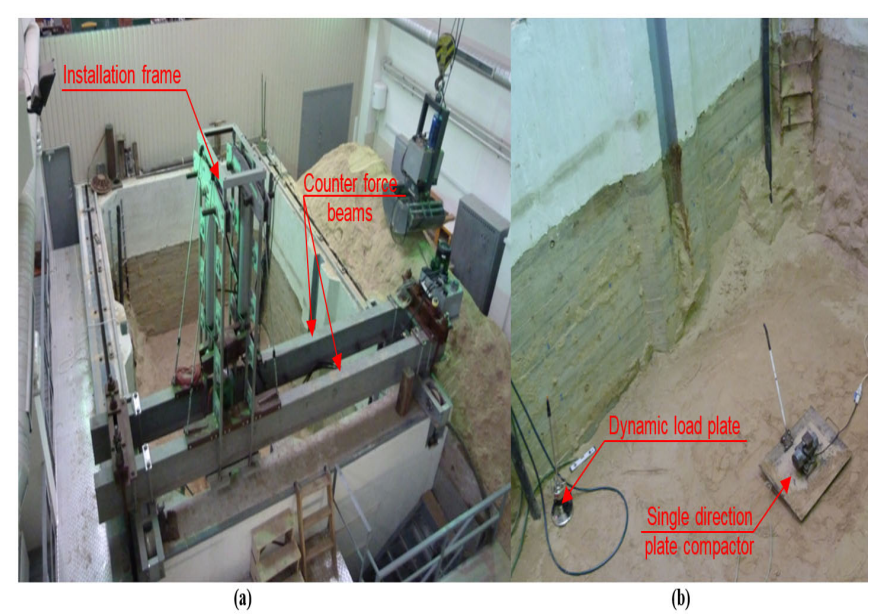

Figure 1. Equipment of specialized soil testing box: (a) itinerant; (b) non itinerant

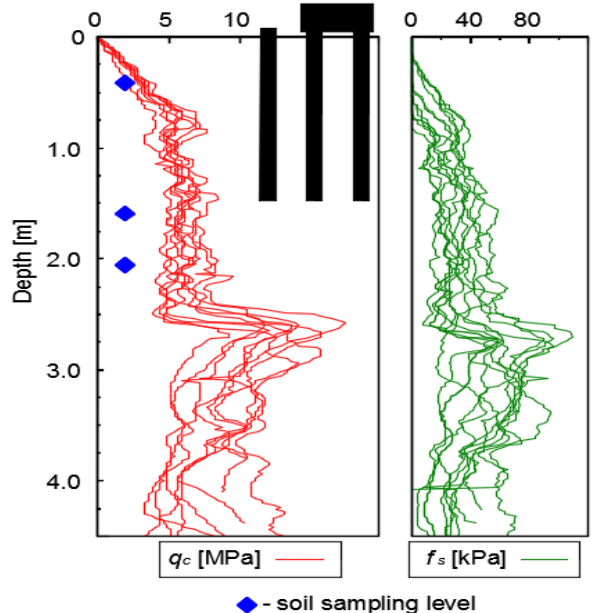

Figure 2. CPT data

Ground resistance measures recorded by loading SDPs and DPGs connected by cap. Model Pile (MP) and Regular Pile (RP) steel pile prototypes employed to perform tests (Figure 3). MP was originally constructed to determine normal stresses $\sigma_{b 1}$ and $\sigma_{b 1}$ on two particular areas $A_{b 1}$ and $A_{b 2}$ of pile base and that of and shear stresses $\tau_{s 1}$ and $\tau_{s 2}$ on two particular areas of pile's skin $A_{s l}$ and $A_{s 2}$. A special constructional scheme for analysis ground resistance of SP and DPG designed and constructed (see Figure 4). The load application and transmitting it to the SPs ensured "hinged" connections structural foundation scheme, conforming the structural model of DPG with "flexible" cap. Piles tested according standard ISO (International Organization for Standardization, 2018). The $s_{u}=0.1 D$ adopted the DP ultimate limit state criterion. The same criterion adopted for DPG. Evolution of SDP and DPG performance analyzed within this interval of loading.

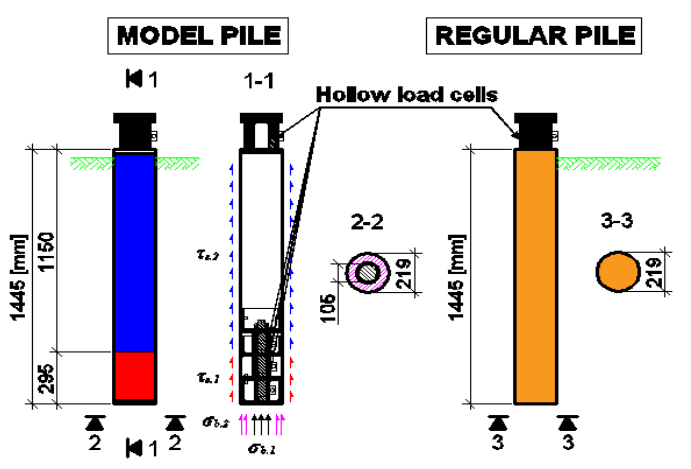

Figure 3. MP and RP schemes

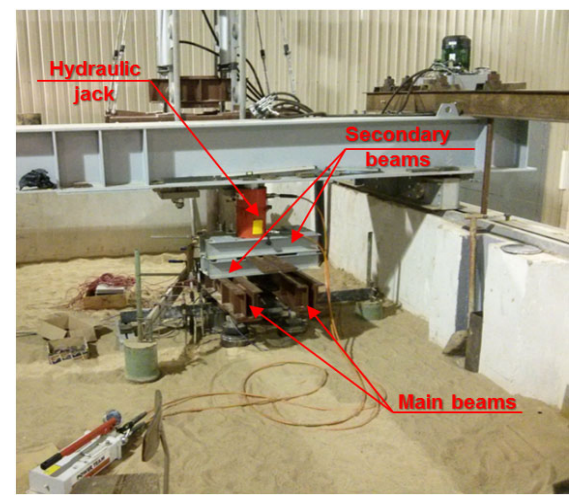

Figure 4. Equipment for testing SDP and DPG

As deformation of short steel piles were negligible comparing with ground deformation, the settlement $s$ adopted equal to pile's head and that of DPG's vertical displacement, respectively. 


\section{Analysis and discussion of single pile and pile group tests}

Aiming to reduce an amount of processed data, the averaging technique applied to illustrate ground resistances of SPs No. 1 and No. 2, that of DPG of No. 1, No. 2 with spacing $a=3 D$ and that of No. 3, No. 4 with spacing $a=2 D$ (Figure 5).

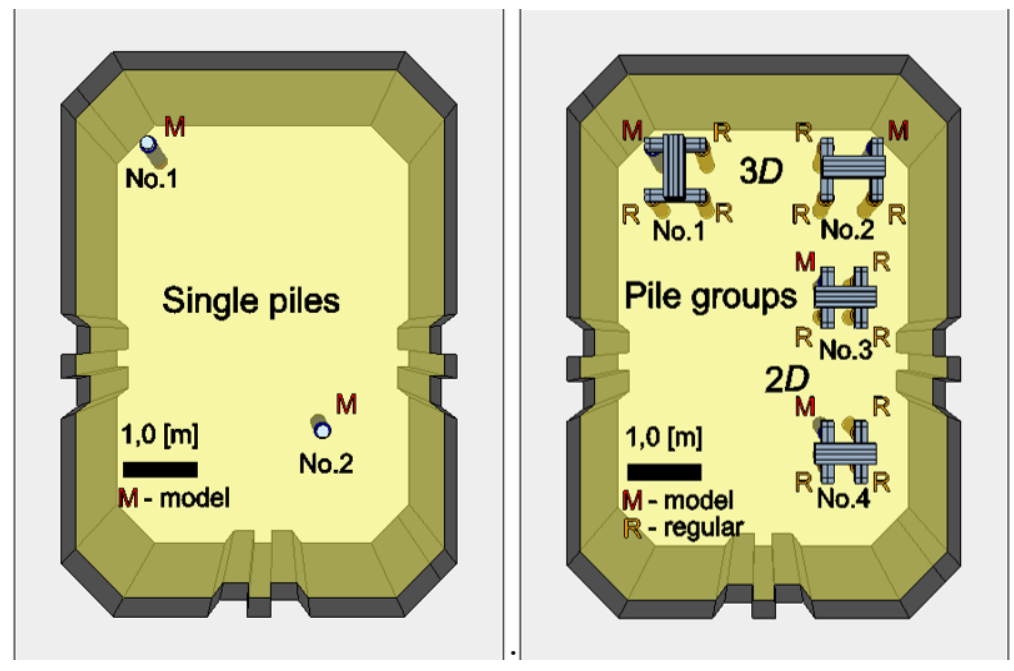

Figure 5. Location of analyzed SDPs and DPGs

The maximum ground resistance force $F$ reached at $s_{u}=0.1 D$ (see Figure 6). The base resisting force $F_{b}=$ $117 \mathrm{kN}$ contribute $76 \%$ of $F$. Consequently, the total shaft resistance force $F_{s}=37 \mathrm{kN}$ contribute $24 \%$ of $F$. The $\tau_{s}$ in the area near pile base accumulated force $F_{s, 1}$, the $7 \%$ of $F$ and $\tau_{s}$ in the upper part of side surface $F_{s, 2}$, the $17 \%$ of $F$. The ratio $F_{b} / F_{s}=3.2$ determines that tested DP was base (tip) bearing piles.

The spacing $a=3 D$ as rational one generally is recommended for design of PG foundations. Tested DPG consisted of 4 symmetrically located SPs connected by flexible cap. The $F$ vs $s$ graphs of SDPs acting in DPG and that of total DPG presented in Figure 7. The DPG maximum load $F_{3 D \text {, max, group }}=640 \mathrm{kN}$ was at $s_{u}=0.1 D$.

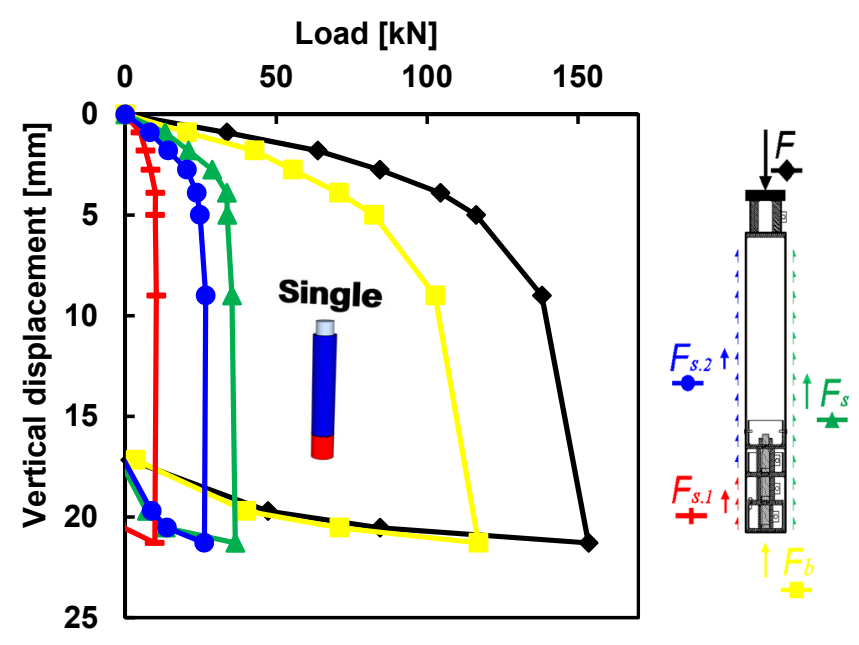

Figure 6. $F_{i}$ vs settlement $s$ graphs of SDP of total, base and shaft resisting forces

Analyzing Figure 8, one can find that resistances of SDPs differ. Secant stiffness (ratio of $F_{3 D \text {, max,group }}$ to $s_{u}=0.1 D$ ) of separate SDPs varied within bounds of $4910 \mathrm{kN} / \mathrm{m}^{`}$ and $9190 \mathrm{kN} / \mathrm{m}^{`}$. Ratio of the largest and the smallest secant stiffness is 1.87 ; that of the average and the smallest ones is 1.4 and that of the largest and the average one is 1.33. As smaller secant stiffness magnitudes were hold by the SDPs installed firstly and the larger ones by those installed after, one can state that ground stiffness distribution under SDPs in DPG depends on installation sequence. 


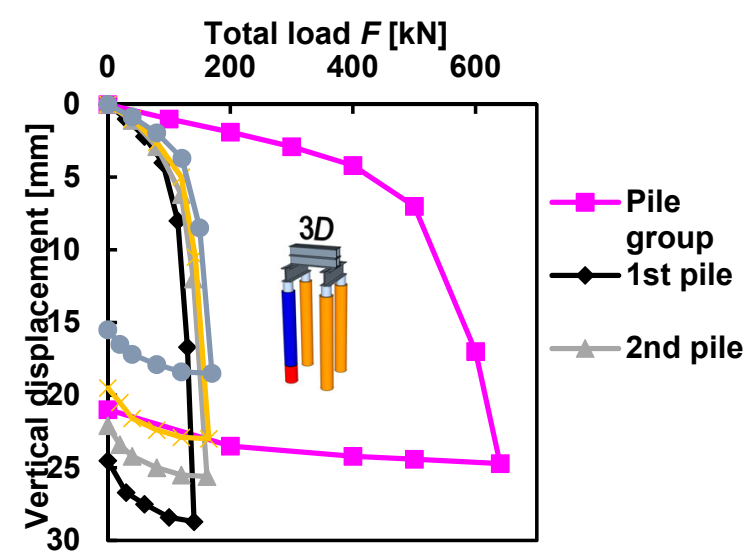

Figure 7. $F$ vs $s$ graph of DPG with spacing $3 D$

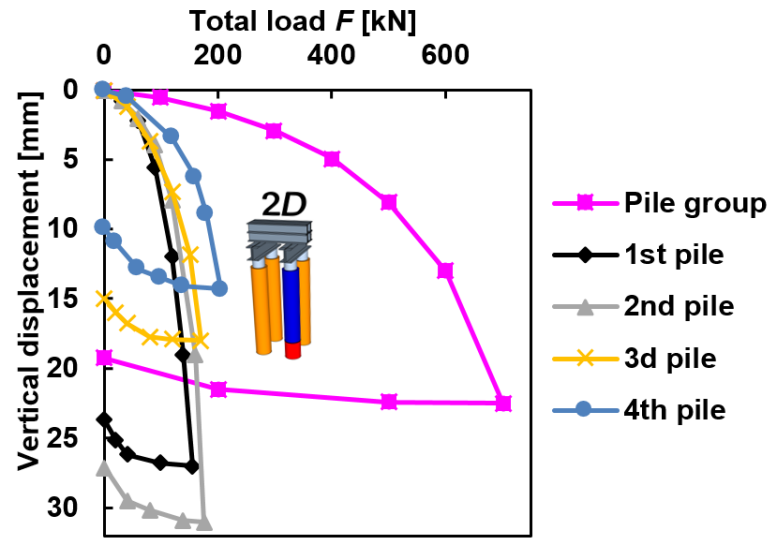

Figure 8. $F$ vs $s$ graph of DPG with spacing $2 D$

The $F$ vs $s$ graph of DPG with spacing a $=2 D$ spacing (see Figure 8) showed, that the sum of four piles $F_{2 D \text { max, group }}$ was equal to $700 \mathrm{kN}$ at $s_{u}=0.1 D$. The stiffness (analogously calculated as for DPG with $a=3 D$ ) of each SDP varied from 5740 up to $14335 \mathrm{kN} / \mathrm{m}$ '.

The bearing resistance vs $s$ peculiarities of DPGs with spacing $a=3 D$ and $a=2 D$ can be determined from their $F$ vs $s$ graphs via comparing them with "fictitious" DPG, created applying the multiplier of magnitude 4 for analogous SDP graph (see Figure 6). All graphs collected in Figure 9. The DPG response character during loading stages differed. In early stages $s=0.03 D$ the "fictitious" DPG resistance was largest and decreased for DPG with smaller spacing $a$, namely: $480 \mathrm{kN}(0 \%) ; 465 \mathrm{kN}(-3 \%) ; 430 \mathrm{kN}(-12 \%)$ for "fictitious" and DPGs with spacing $a=3 D$ and $a=2 D$, respectively. At $s_{u}=0.1 D$ the result was the opposite: $616 \mathrm{kN}(0 \%) ; 640 \mathrm{kN}(4 \%) ; 700 \mathrm{kN}(14 \%)$.

0

Total load $F[\mathrm{kN}]$
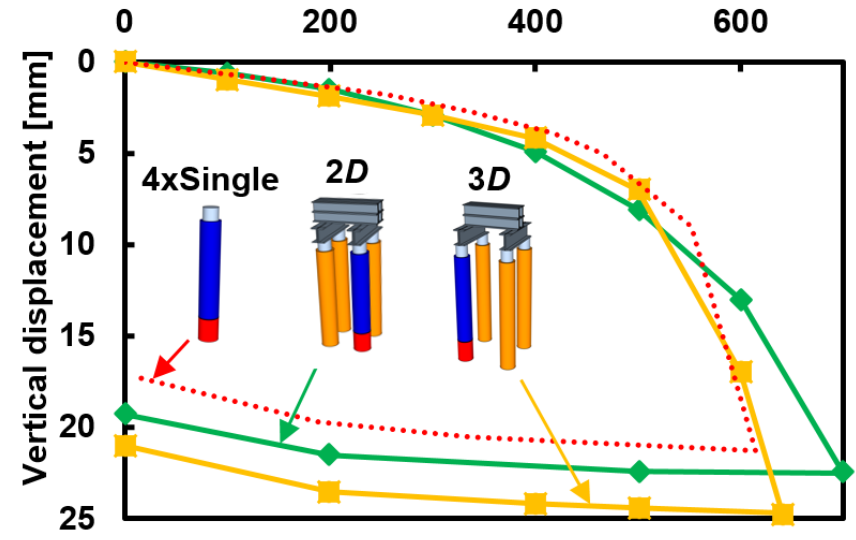

Figure 9. $F$ vs $s$ graphs of DPGs with spacing $2 D$ and $3 D$ and of "fictitious" DPG created from averaged $F$ vs $s$ graph of SDP

One can find from Figure 9 that $F$ vs $s$ graph character of DPG with spacing $a=3 D$ is more similar to SDP behaviour, that of the DPG with spacing $a=2 D$ is more similar to shallow foundation behaviour, as characterized by more uniform performance. Analyzing the maximum and minimum stiffness of PDGs (see Figures 7 and 8) one can find that uniformity of maximum and minimum secant soil-pile stiffness is up to 77\% higher for DPG with $a=2 D$.

\section{Conclusions}

The DPG efficiency factor $\eta$ for loading up to $s<0.1 D$ is in good agreement with the ones according Vesic and Tejchman predictions, but is in conflict with the ones, determined according Broms, Kishida and Sales et al. predictions, yielding $\eta<1$.

Comparing the shapes of the load vs settlement curves for DPG with spacings $a=3 D$ and $a=2 D$ (see Figures 7 and 8), one can find that DPG with $a=2 D$ that is more similar to a shallow foundation response than to a single displacement pile behaviour. This phenomenon shows the formation of the conditional block and subsequent failure when increasing load, the phenomenon that according Fleming recognized to be met exceptionally in clays.

The significant difference of pile response in terms of stiffness subjected to the installation sequence was determined. The maximum and minimum stiffness of DPG with $a=2 D$ differed up to 2.5 times. The stiffness of individual 
pile in DPG with $a=2 D$ differed up to $154 \%$. This result is in conflict with Sales et al. findings, stating the installation effects are negligible. From practical point of view this phenomenon might cause a rotation of supported structure, consequently inducing additional internal forces which should lead to underestimation on structure's stiffness and bearing capacity. This effect should be taken in to account in design of constructional system: superstructure-foundation-ground.

The SDP response in principle changes for DPGs with spacing of a $=2 D$ and $a=3 D$ under different settlement magnitudes. Small (up to $s=0.03 D$ ) settlements are characteristic to serviceability requirements of superstructure. Within this $s$ interval the DPG stiffness reduce when spacing $a$ reduce. The contrary result obtained when $s_{u} \geq 0.1 D$, id. est. for the settlements corresponding the ultimate limit state requirements of foundation. DPG stiffness increase when the spacing $a$ reduce; it is also stiffer the "fictitious" DPG, created of separate SDPs. This result is in agreement with Zhang et al. findings.

The obtained test results of DPS and DPGs illustrated that currently proposed methods for predicting pile group behavior measures are very scattered, even in conflict. The installation of DPs sequence factor found to be an important one for predicting DPG efficiency and response measures. The effect should be properly evaluated in design process, together with already recognized factors for DPG resistance measures as slenderness, pile spacing, relative density and cap stiffness. The results of performed experimental study prove necessity of specialized complementary tests with the aim of development of DPG behavior predictions methods, also applying numerical modelling techniques in concert with validation and calibration procedures.

\section{References}

Bhasi, A., Rajagopal, K., \& Reddy, V. (2010). Finite element study of the influence of pile jetting on load capacity of adjacent piles. International Journal of Geotechnical Engineering, 4(3), 361-370. https://doi.org/10.3328/IJGE.2010.04.03.361-370

Broms, B. B. (1981). Pre-cast piling practice. UK: Thomas Telford.

Comodromos, E. M., Anagnostopoulos, C. T., \& Georgiadis, M. K. (2003). Numerical assessment of axial pile group response based on load test. Computers and Geotechnics, 30(6), 505-515. https://doi.org/10.1016/S0266-352X(03)00017-X

European Committee for Standardization. (2004). Eurocode 7: Geotechnical design - Part 1: General rules (EN 1997 - 1:2004). Retrieved from https://www.ngm2016.com/uploads/2/1/7/9/21790806/eurocode_7_-_geotechnical_designen.1997.1.2004.pdf

Fleming, K., Weltman, A., Randolph, M., \& Elson, K. (2009). Piling engineering. Abingdon: Taylor \& Francis.

International Organization for Standardization. (2018). Geotechnical investigation and testing - Testing of geotechnical structures Part 1: Pile load test by static axially loaded compression (ISO 22477-1:2018).

Kishida, H. (1964). The bearing capacity of pile groups under central and eccentric loads in sands (Report No. 19). Building Research Institute, Ministry of Construction, Japanese Gov.

Martinkus, V., Norkus, A., Statkus, T., \& Zilioniene, D. (2014). Experimental investigation of stresses in sand during the installation and loading of the short displacement pile. The Baltic Journal of Road and Bridge Engineering, 9(1), 10-16. https://doi.org/10.3846/bjrbe.2014.02

McCabe, B. A., \& Lehane, B. M. (2006). Behaviour of axially loaded pile groups driven in clayey silt. Journal of Geotechnical and Geoenvironmental Engineering, 132(3), 401-410. https://doi.org/10.1061/(ASCE)1090-0241(2006)132:3(401)

Mylonakis, G., \& Gazetas, G. (1998). Settlement and additional internal forces of grouped piles in layered soil. Geotechnique, 8(1), 55-72. https://doi.org/10.1680/geot.1998.48.1.55

Randolph, M. F., \& Wroth, C. P. (1979). An analysis of the vertical deformation of pile groups. Geotechnique, 29(4), $423-439$. https://doi.org/10.1680/geot.1979.29.4.423

Randolph, M. F. (2003). 43 ${ }^{\text {rd }}$ Rankine Lecture: Science and empiricism in pile foundation design. Geotechnique, 53(10), 847-875. https://doi.org/10.1680/geot.2003.53.10.847

Sales, M. M., Prezzi, M., Salgado, R., Choi, Y. S., \& Lee, J. (2017). Load-settlement behavior of model pile groups in sand under vertical load. Journal of Civil Engineering and Management, 23(8), 1148-1163. https://doi.org/10.3846/13923730.2017.1396559

Tejchman, A. F. (1973). Model investigation of pile group in sand. Journal of Soil Mechanics and Foundation Division, $2,99-215$.

Vesic, A. S. (1969). Experiments with instrumented pile group in sand. In R. Lundgren \& E. D'Appolonia (Eds.), STP444-EB Performance of Deep Foundations (pp. 177-222). https://doi.org/10.1520/STP47286S

Zhang, Q.-Q., Zhang, S.-M., Liang, F.-Y., Zhang, Q., \& Xu, F. (2015). Some observations of the influence factors on the response of pile groups. KSCE Journal of Civil Engineering, 19(6), 1667-1674. https://doi.org/10.1007/s12205-014-1550-7 